\title{
Propriedades tensiométricas do peritônio da paca (Cuniculus paca) a fresco e conservado em glicerina $98 \%{ }^{1}$
}

\author{
Angela Daniele de Camargo ${ }^{2}$, Paulo César de Camargo ${ }^{3}$, Leonardo Martins Leal ${ }^{2}$, \\ Sérgio Pinter Garcia Filho ${ }^{2 *}$, Leandro Luís Martins ${ }^{2}$, Antônio Carlos Shimano ${ }^{4}$ \\ e Márcia Rita Fernandes Machado²
}

\begin{abstract}
Camargo A.D., Camargo P.C., Leal L.M., Garcia Filho S.P., Martins L.L., Shimano A.C. \& Machado M.R.F. 2014. [Tensiometer peritoneum properties of the paca (Cuniculus paca) fresh and preserved in glycerin 98\%.] Propriedades tensiométricas do peritônio da paca (Cuniculus paca) a fresco e conservado em glicerina 98\%. Pesquisa Veterinária Brasileira 34(2):185-191. Departamento de Morfologia e Fisiologia Animal, Universidade Estadual Julio de Mesquita Filho, Campus Jaboticabal, Via de Acesso Prof. Paulo Donato Castellane s/n, Jaboticabal, SP 14884-900, Brazil. E-mail: sgarciafilho@hotmail.com

In constant searching for alternative biological material to perform implants and new options of experimental animal models, the objective of this investigation was to describe the mechanical properties of the peritoneum paca (Cuniculus paca Linnaeus, 1766) fresh and preserved in $98 \%$ glycerin. Samples of fresh and preserved in glycerin for periods of 30, 60 and 90 days were subjected to mechanical tests. Four adult animals, male or female, with mean body weight of eight kilograms, were used for collecting samples of the peritoneum. All tissues preserved in glycerin $98 \%$ showed a decrease in stiffness and increase in ductility and toughness. Considering the maximum force applied to the peritoneum, significant increase was observed in values $(\mathrm{p}<0.01)$ of samples stored for 60 and 90 days when compared to fresh material. In relation to the stretch variable, an increase was observed in all storage time of glycerin samples, verifying significant difference $(p<0,01)$ when compared with the fresh samples. The variable area also showed significance $(\mathrm{p}<0.01)$ between the values of the fresh samples $\left(5.40 \mathrm{~mm}^{2}\right)$ and preserved in the glycerin by periods of 30 days $\left(4.50 \mathrm{~mm}^{2}\right), 60$ days $\left(9.00 \mathrm{~mm}^{2}\right)$ and 90 days $\left(7.20 \mathrm{~mm}^{2}\right)$, thus indicating that the area of this membrane increased by 0.033 $\mathrm{mm}^{2}$ per day. Generally, it was concluded that the $98 \%$ glycerin is a substance effective for the preservation of the peritoneum of the agouti paca, therefore improves its mechanical properties allowing the support membranes greater deformation forces. Thus, the results obtained in mechanical tests of the peritoneum of paca suggest its use as an alternative biological material.
\end{abstract}

INDEX TERMS: Cuniculus paca, paca, peritoneum, mechanical tests, biological membranes, reconstruction, surgery

\footnotetext{
${ }^{1}$ Recebido em 24 de setembro de 2013.

Aceito para publicação em 23 de fevereiro de 2014.

${ }^{2}$ Departamento de Morfologia e Fisiologia Animal, Universidade Estadual Julio de Mesquita Filho, Campus Jaboticabal, Via de Acesso Prof. Paulo Donato Castellane s/n, Jaboticabal, SP 14884-900, Brasil. *Autor para correspondência: sgarciafilho@hotmail.com

${ }^{3}$ Departamento de Física, Setor de Ciências Exatas, Universidade Federal do Paraná (UFPR), Cx. Postal 19044, Curitiba, PR 81531-990, Brasil.

${ }^{4}$ Departamento de Biomecânica, Medicina e Reabilitação do Aparelho Locomotor, Faculdade de Medicina de Ribeirão Preto, Universidade de São Paulo, Av. Bandeirantes 3900, Ribeirão Preto, SP 14049-900, Brasil.
}

RESUMO.- Na busca constante, tanto de material biológico alternativo para a realização de implantes, quanto de novas opções de modelos de experimentação animal, o objetivo desta investigação foi descrever o comportamento mecânico do peritônio da paca (Cuniculus paca Linnaeus, 1766) a fresco e conservado em glicerina a $98 \%$. Amostras frescas e conservadas em glicerina por períodos de 30,60 e 90 dias foram submetidas a testes mecânicos de tração. Quatro animais adultos, três machos e uma fêmeas, com peso corporal médio de oito quilogramas, foram utilizados para colheita 
das amostras de peritônio. Todos os tecidos conservados em glicerina a 98\% apresentaram diminuição na rigidez e aumento na ductibilidade e tenacidade. Considerando-se a força máxima aplicada ao peritônio, evidenciou-se aumento significativo nos valores $(\mathrm{p}<0,01)$ das amostras conservadas por 60 e 90 dias, quando comparado ao material a fresco. Com relação a variável alongamento, notou-se aumento nos valores relativos aos materiais em glicerina em todos os tempos de conservação, verificando-se diferença significativa $(p<0,01)$ entre os valores das amostras a fresco. A variável área também se apresentou significativa $(p<0,01)$ entre os valores das amostras a fresco $(5,40$ $\mathrm{mm}^{2}$ ) e os preservados em glicerina pelos períodos de 30 dias $\left(4,50 \mathrm{~mm}^{2}\right), 60$ dias $\left(9,00 \mathrm{~mm}^{2}\right)$ e 90 dias $\left(7,20 \mathrm{~mm}^{2}\right)$, indicando assim, que a área desta membrana aumentou em $0,033 \mathrm{~mm}^{2}$ por dia. Mediante os resultados observados, concluiu-se que a glicerina 98\% é uma substância eficiente para a conservação do peritônio da paca, pois melhorou suas propriedades mecânicas permitindo que as membranas suportem maiores forças de deformação. Assim, os resultados obtidos nos ensaios mecânicos do peritônio da paca sugerem sua utilização como mais uma opção de material biológico.

TERMOS DE INDEXAÇÃO: Cuniculus paca, paca, peritônio, ensaios mecânicos, membrana biológica, reconstrução, cirurgia.

\section{INTRODUÇÃO}

O emprego de membranas biológicas, como material de implante, para a reparação de vísceras e outras estruturas anatômicas na medicina veterinária, iniciou-se com o trabalho de Pigossi (1964) mediante utilização de dura-máter homóloga de cães conservada em glicerina. 0 uso de membranas biológicas deve-se, especialmente, ao baixo custo, simples preparo, esterilização viável, além da facilidade em sua obtenção, estocagem e utilização, salientando-se, neste caso, a ocorrência de pouca ou nenhuma reação tecidual (Alvarenga 1992).

Enfermidades que possam comprometer a função normal de um órgão, tais quais, neoplasias, traumatismos, abscessos, nódulos parasitários, entre outras, suscitaram não só a ampla utilização de implantes nas últimas décadas (Batista 1996), como também, a realização de pesquisas com membranas biológicas visando avaliar sua viabilidade em procedimentos cirúrgicos nas diferentes regiões do organismo animal (Pigossi et al. 1971, Daleck et al. 1988, Alvarenga 1992, Rodaski et al. 2002, Saporito et al. 2011).

Dentre as membranas biológicas estudadas, destacam-se o centro tendíneo, a dura-máter, a fáscia lata, o pericárdio e o peritônio (Alvarenga 1992). Entre estas se enfatiza o uso do peritônio bovino, composto quase que exclusivamente de colágeno que lhe confere baixa antigenicidade e permite seu uso corrente como prótese biológica; também fornece uma área maior de tecido aproveitável, a qual se adapta às diversas situações da prática cirúrgica (Daleck et al. 1988).

Ressalta-se a utilização da cartilagem auricular por vários autores em cirurgias reparadoras, como se verifica nas pesquisas de Chehuen Neto et al. (1991) que a utilizaram para a restauração de traquéia; nos estudos de Pigatto et al. (1998) referentes a esofagoplastia em cães, nos de Contesini et al. (2001a) sobre a reparação traqueal em cães; nos de Contesini et al. (2001b) no reparo tardio de fenda palatina em cães; também em sua aplicação em acetabuloplastia extracapsular de cães (Costa et al. 2004) e nas observações de Baungarten et al. (2006) ao empregarem-na nos casos de blefaroplastia em coelhos.

Para evitar a rejeição, estas membranas devem permanecer preservadas, por período mínimo de 30 dias, em glicerina (Pigossi 1964, Pigossi et al. 1971, Daleck et al. 1992, Sartori filho et al. 1997, Costa Neto et al. 1999), embora possam ser conservadas neste mesmo meio, por período de até seis meses ou mais (Pigossi 1967).

A glicerina desidrata o tecido e remove a maior parte da água intracelular, sem, contudo, alterar as concentrações iônicas das células, sendo assim eficaz fixador e protetor da integridade celular. Aumenta resistência à tração e não altera a elasticidade. Age ainda como poderoso antisséptico, exceto contra as formas esporuladas. A ausência de reações inflamatórias agudas dos implantes indica a baixa antigenicidade do transplante obtido por este meio de conservação. Além disso, a glicerina apresenta baixo custo, facilidade de manuseio (Leite et al. 1979) e é biologicamente inerte e aprovada pelo Food and Drug Administration (FDA) na composição de cosméticos e medicamentos de uso tópico (Wells et al. 2006).

Considerando-se que por meio de ensaios biomecânicos determinam-se as propriedades mecânicas de um material, o qual, dependendo de suas características físicas, poderá submeter-se a ensaios de tração, torção, compressão e flexão (Batista et al. 1996), julga-se que para complementar os experimentos atinentes ao emprego de membranas biológicas, como implantes, seja fundamental a realização desse tipo de estudo, e assim avaliar as propriedades biomecânicas de uma membrana que poderá ser utilizada clinicamente.

$\mathrm{Na}$ busca constante, tanto de material biológico alternativo para a realização de implantes, quanto de novas opções de modelos de experimentação animal, surge a paca (Agouti paca), segundo maior roedor da região neotropical, com até $80 \mathrm{~cm}$ de comprimento corpóreo e $12 \mathrm{~kg}$ de peso. Apresenta quatro dígitos nos membros torácicos e cinco nos membros pélvicos. É excelente nadadora e quando se sente ameaçada procura abrigos em lagos ou rios (Pachaly et al. 2001).

Com tempo médio de sobrevida de 16 anos, essa espécie de roedor está presente em grande parte do território brasileiro e distribui-se geograficamente desde o sudeste do México até o sul do Paraguai e norte da Argentina, em altitudes de até 3.000 metros (Eisenberg \& Redford 1999, Lange \& Schmidt 2007, Queirolo et al. 2008).

As observações de Hamlett \& Rasweiler IV (1993) devem ser ponderadas, pois evidenciam a necessidade da busca de novos exemplares, entre os animais, para serem utilizados como modelos experimentais adequados e assim colaborarem com o desenvolvimento de pesquisas vitais, tanto ao homem, quanto a outras espécies e a paca, como componente da fauna silvestre brasileira, até o momento 
não teve sua morfologia amplamente estudada, merecendo maior atenção dos pesquisadores da área, pois existem ainda grandes lacunas quanto à descrição especifica de muitos de seus aspectos anatômicos.

As características morfológicas do peritônio da paca a fresco e conservadas em glicerina a 98\%, por períodos de 30, 60 e 90 dias foram avaliadas por Camargo et al. (2012) por meio de microscopia de luz e microscopia eletrônica de varredura. Os autores verificaram, em ambas amostras de peritônio, fresco e conservada, um evidente arranjo entre o tecido conjuntivo denso modelado e o tecido conjuntivo denso não modelado, com insignificante modificação na integridade tecidual do peritônio da paca conservado em glicerina.

Diante de tais informaçõesobjetivou-se descrever o comportamento do peritônio da paca, quando submetido a ensaios mecânicos de tração, estando essa membrana, tanto fresca quanto conservada em glicerina a 98\%, durante 30, 60 e 90 dias.

\section{MATERIAL E MÉTODOS}

A metodologia adotada no desenvolvimento do presente estudo foi aprovada pela Comissão de Ética e Bem Estar Animal (CEBEA) da Faculdade de Ciências Agrárias e Veterinárias (FCAV), Campus de Jaboticabal da Universidade Estadual Paulista Julio de Mesquita Filho (Unesp), segundo o protocolo nํㅜ 010455.

\section{Coleta do peritônio}

Foram utilizadas quatro pacas, sendo três machos e uma fêmea, todas adultas com peso médio de oito quilogramas. Os animais pertenciam ao plantel de pacas do setor de Animal Silvestres da FCAV, Unesp-Campus de Jaboticabal, que é registrado no Instituto Brasileiro do Meio Ambiente e dos Recursos Naturais Renováveis (Ibama), como criatório de espécimes da fauna brasileira para fins científicos.

Logo após a morte, o animal, foi posicionado em decúbito dorsal, mediante incisão pré-retroumbilical na linha mediana visibilizou-se a face interna da parede abdominal, que é revestida por peritônio parietal em toda sua extensão, iniciou-se a colheita desta membrana, descolando-a cuidadosamente, tanto da parede abdominal direita, quanto da esquerda (Fig.1).

Mesmo levando-se em conta a irregularidade desse revestimento, procurou-se manter certa homogeneidade entre as amostras. As amostras foram lavadas em solução fisiológica para retirada de resíduos. Aquelas que foram encaminhadas para as avaliações a fresco foram acondicionadas, individualmente, em recipientes plásticos contendo solução fisiológica de $\mathrm{NaCl} 0,9 \%$. As que foram avaliadas em períodos diferentes de conservação em glicerina a 98\%, também foram conservadas individualmente em recipientes plásticos, que neste caso continham glicerina a 98\%, em uma proporção de 20:1 (glicerina/ membrana), permanecendo neste meio durante os períodos de 30,60 e 90 dias.

Todos os recipientes foram devidamente identificados (nome

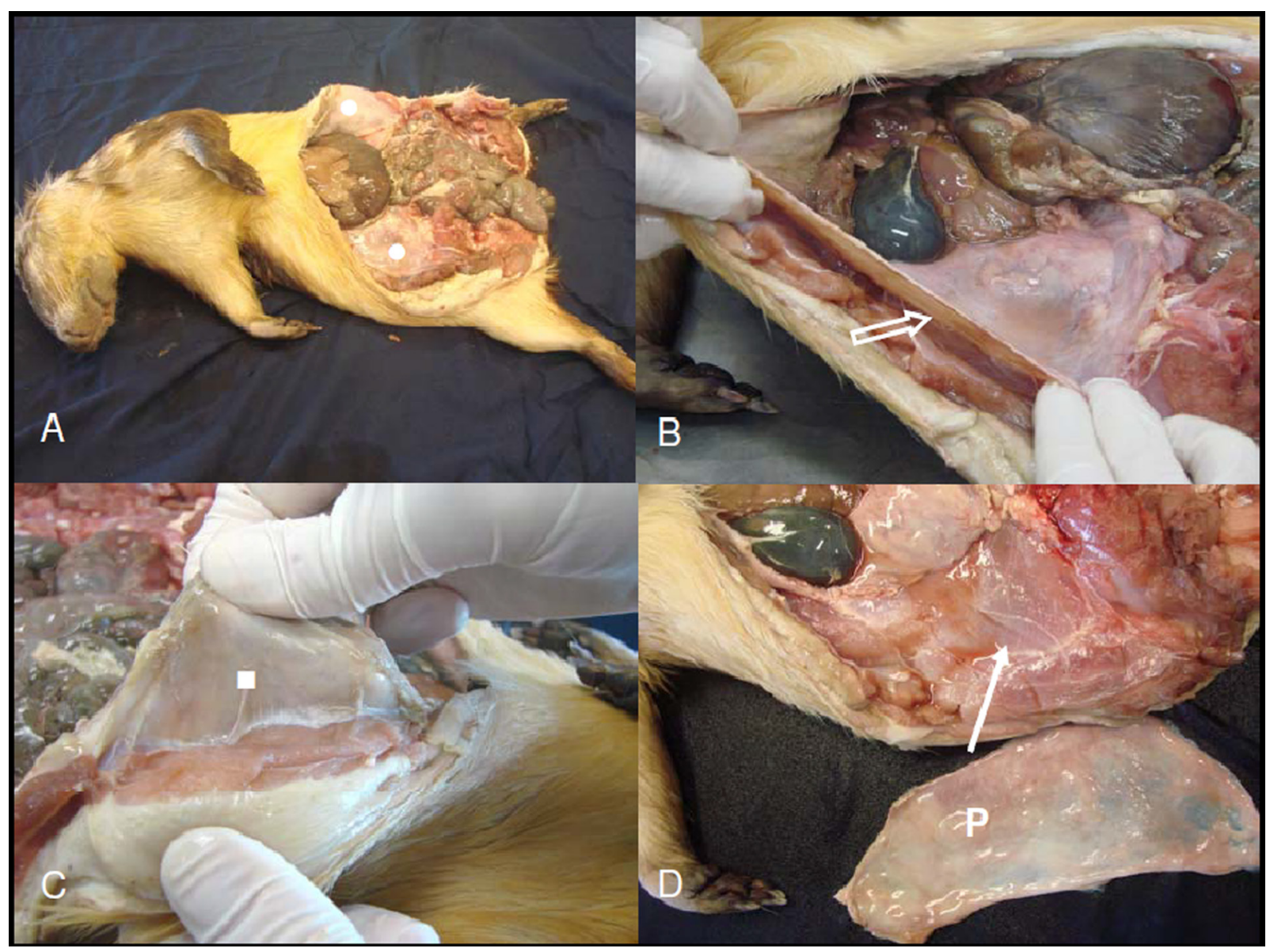

Fig.1. Colheita do peritônio. (A) Observa-se a localização do peritônio revestindo as paredes abdominais laterais de uma paca adulta $(\bullet)$. (B,C) Descolamento parcial do peritônio parietal (seta vazada), o qual está bem evidenciado ( $\mathbf{})$ em C. (D) Retalho peritonial (P) e o local da parede abdominal lateral (seta), de onde foi colhido. 
do material, data da colheita e meio de preservação) e todas as amostras mantidas em temperatura ambiente.

\section{Ensaios mecânicos}

As provas de ensaios mecânicos de tração foram realizadas no laboratório de Bioengenharia da Faculdade de Medicina de Ribeirão Preto, USP. Para a avaliação do material procedeu-se inicialmente a obtenção das amostras, que se constituíram de 10 retalhos peritoniais com aproximadamente, $10 \mathrm{~mm}$ de largura e 150 mm de comprimento, para cada animal.

A confecção dessas amostras foi realizada inicialmente, mediante a lavagem em solução fisiologia de $\mathrm{NaCl}$ 0,9\%, e limpeza do material, para a retirada de possíveis resíduos, gorduras e aderências remanescentes. Em seguida esse material passou por uma guilhotina adaptada, que constava de uma plataforma de apoio e duas navalhas paralelas, distantes $10 \mathrm{~mm}$ entre si, e obteve-se as amostras que constavam de retalhos peritoneais.

Os retalhos obtidos foram reidratados em solução fisiológica de $\mathrm{NaCl}$ 0,9\% por 20 minutos. A partir dai, foram realizados os testes em máquina universal de ensaio EMICR1 (modelo DL10000). A máquina possui interface direta a um microcomputador, com um software $\operatorname{Tesc}^{\circledR}$, capaz de gerar gráficos da carga versus alongamento para cada ensaio.

Para fixação dos corpos de prova na máquina foi utilizado acessório que contém ranhuras em sua superfície, as quais auxiliam esse processo, mediante compressão realizada pelo ajuste de um parafuso, evitando o escorregamento do material durante o ensaio.

No momento dos ensaios, os corpos de prova foram acoplados à maquina dada uma pré-carga de $1 \mathrm{~N}(100 \mathrm{~g})$ por aproximadamente 30 segundos, para que houvesse a acomodação do sistema, evitando-se possíveis folgas no conjunto máquina, acessório e modelo ensaiado.

Com a amostra já acoplada na máquina, foi realizada a mensuração de sua largura e espessura com o auxilio de paquímetro Mytutoyo ${ }^{\circledR}$, e após essa mensuração se processou o ensaio propriamente dito.

Após a pré-carga o ensaio prosseguiu, em média, por $5 \mathrm{~min}$, com velocidade pré-estabelecida em $10 \mathrm{~mm} / \mathrm{min}$. A carga aplicada foi registrada pelo software em intervalos regulares de alongamento até o momento da ruptura das membranas.

Foram obtidos gráficos com o registro da carga "versus" alongamento de cada ensaio, nos quais foram analisadas as seguintes propriedades mecânicas: força máxima, tensão máxima, espessura e alongamento.

A forca máxima é definida como aquela suportada antes do início da ruptura completa de um tecido ou parede, sem considerar suas dimensões, calculada em Newton. A tensão é medida em termos de quantidade de força suportada por unidade de área de secção, ou seja, independe da área da seção transversal do tecido, sendo calculada em N/mm2 e expressa em MPa (mega pascal). Ela permite comparações mais adequadas entre corpos de prova de diferentes membranas. Assim, faz-se necessário o cálculo da área de secção transversal inicial da estrutura avaliada, e qualquer que seja a área inicial, o valor da tensão não se altera. 0 alongamento é calculado em mm e é dado pela distensão do material registrado no ponto de aplicação da carga máxima (Schaum \& Van der Merwe, 1973).

Os autores relatam o valor da carga de $1 \mathrm{~N}$ utilizada para a acomodação do sistema e definem a força máxima, mas não relatam como ela será determinada. Como que esta força máxima será determinada? Será por estímulo elétrico? Se for, qual a intensidade em $\mathrm{Hz}$ que foi utilizada?

Considerando-se que com este estudo busca-se estabelecer parâmetros mecânicos que sejam relevantes dentre as possibili- dades e a conveniência da utilização do peritônio de paca como implante, optou-se por analisar os parâmetros elásticos característicos com os respectivos algarismos significativos, determinados com base no erro provável, levando-se em conta os instrumentos, as amostras e as condições de medidas. Optou-se pela estimativa de erros intrínsecos de cada medida nas curvas de força por deslocamento, procurando-se observar tendências gerais e buscando fornecer ao leitor um parâmetro equivalente ao módulo de Young da mecânica, que corresponde a tensão mecânica em MPa dividida pela taxa de deformação em trechos lineares, com números de pontos escolhidos arbitrariamente.

Os erros indicados para as medidas individuais correspondem a uma estimativa plausível considerando os instrumentos, as condições de realização das medidas e a propagação do erro nas operações de multiplicação e de divisão realizadas, com o objetivo de representar-se o número Máximo aceitável de algarismos significativos. A estimativa de erro da força máxima considerou os valores típicos em torno do valor Máximo, assim como na determinação do alongamento na posição de Máximo. As principais fontes de erro são as medidas de largura e de espessura. 0 erro na determinação da espessura e da largura das membranas é intrínseco do material que não tem geometria fixa e bem determinada.

Tomando a linha do corpo de prova de número um, como exemplo, vê-se que o erro na espessura, com valor de $0,50 \mathrm{~mm}$ foi considerado $\pm 0,05 \mathrm{~mm}$, o que corresponde a metade de $0,1 \mathrm{~mm}$ que é a menor leitura que se consegue determinar com confiança razoável. Assim a leitura correta deve estar entre 0,55 e 0,65.

No caso da largura, todas as amostras foram cortadas com 10 mm. Observando a não uniformidade e irregularidades das amostras, estimou-se um erro de $\pm 1 \mathrm{~mm}$, ou seja, as larguras reais deverão estar de 10-1 = 9mm e 10+1 = 11mm.

Os erros nas medidas de espessura e largura não são aleatórios, assim não foi determinado seu valor médio. Os erros nas áreas foram calculados considerando que na multiplicação os erros relativos se somam. A estimativa de erro na força máxima e na deformação neste ponto foi obtida diretamente da leitura das coordenadas correspondentes a força e a deformação nas vizinhanças destes pontos. A tensão expressa em mega Pascal (MPa) foi obtida dividindo-se a força pela área correspondente. 0 erro na tensão foi obtido a partir da soma dos erros relativos na área, somado ao erro relativo da leitura da força máxima.

A força máxima depende diretamente da área da secção transversal inicial, assim existe um erro sistemático que compromete o uso da estatística, pois, naturalmente a força máxima será menor para áreas de secção transversal menores. 0 máximo alongamento também depende das peculiaridades das amostras e da secção transversal, assim o erro nesta variável é não aleatório.

\section{Análise estatística}

Os resultados apresentados foram todos tratados com o programa Microsoft Origin 6.0 e também foram submetidos a uma análise estatística a fim de preservar, para comparação, o melhor método de avaliação dos dados de trabalhos anteriores. Nesta prova os dados foram comparados pelo teste $\mathrm{F}$ da análise de variância, e quando significativo ajustaram-se polinômios ortogonais para melhor explicar estas diferenças. Todos os resultados da análise estatística foram obtidos no "software" Minitab (1992).

\section{RESULTADOS}

Observam-se no Quadro 1 os valores de força máxima, tensão máxima, tensão media dos valores máximos, deformação máxima para os ensaios realizados.

Para a obtenção de parâmetros característicos do peritônio da paca considerou-se que as amostras estudadas 
Quadro 1. Valores de força máxima, tensão máxima, tensão media dos valores máximos, deformação máxima para os ensaios realizados com a membrana de peritônio de paca. (Deformação máxima é relativa ao comprimento inicial que é de $5,0 \mathrm{~cm}$ )

\begin{tabular}{lcccc}
\hline Parâmetros & \multicolumn{4}{c}{ Períodos analisados (dias) } \\
\hline & 0 & 30 & 60 & 90 \\
Força máxima (N) & 14 & 16 & 22 & 31 \\
Tensão máxima (MPa) & 2,8 & 2,8 & 4,0 & 3,8 \\
Tensão média do valores & 1,84 & 1,74 & 1,74 & 2,8 \\
máximos (MPa) & & & & \\
Deformação máxima (cm) & 0,30 & 0,49 & 0,78 & 0,93
\end{tabular}

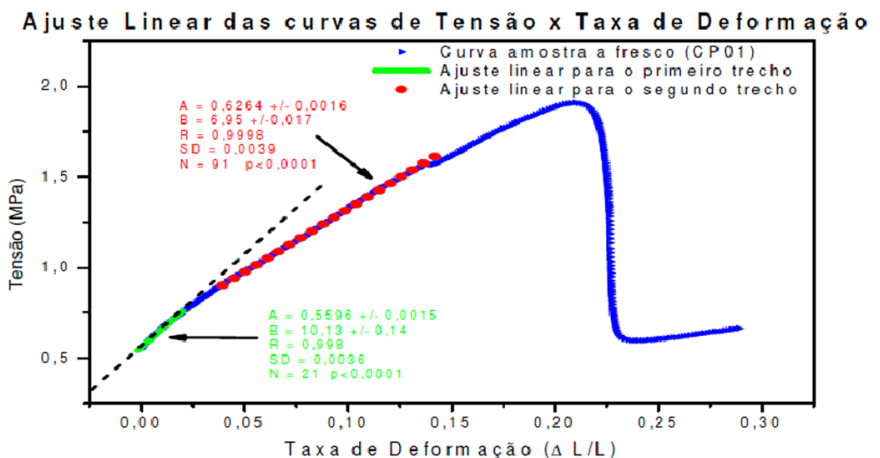

Fig.2. Representação gráfica dos pontos em dois trechos considerados lineares. Nota-se que no trecho inicial (preto tracejado) a constante elástica é de 10,1 MPa, enquanto que no segundo trecho o valor e de 6,95 MPa. Este valor decresce na medida em que as deformações crescem mostrando claramente o comportamento não linear deste material. Assim julga-se estabelecer a ordem de grandeza da constante elástica do material que esta entre $1 \mathrm{MPa}$ e, aproximadamente $10 \mathrm{MPa}$, neste caso.

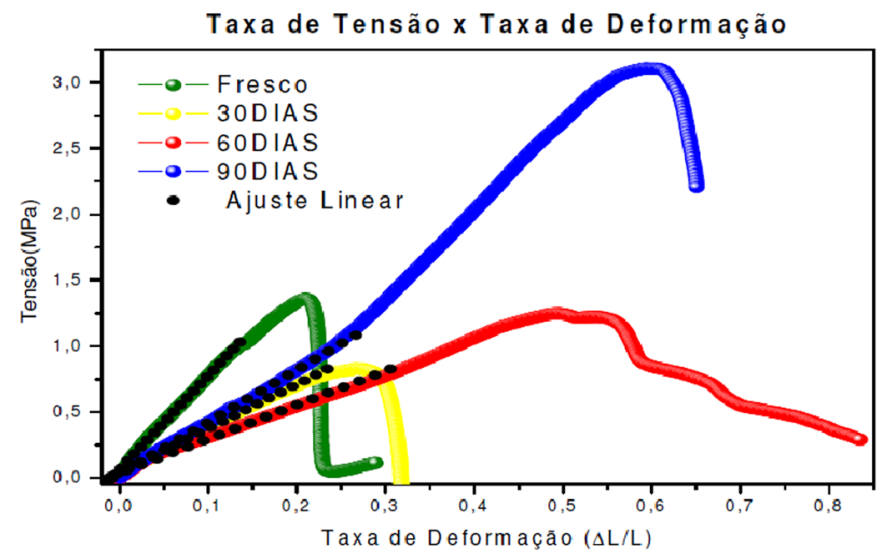

Fig.3. Representação gráfica do ajuste linear nos diferentes períodos analisados.

não seguiam um padrão linear na curvas que relacionam força e deformação, optando-se por escolher pontos arbitrários somente em trechos considerados lineares como se verifica na Figura 2.

Uma visão geral do comportamento da tensão x taxa de deformação nas condições; fresco, 30, 60 e 90 dias conservadas em glicerina a $98 \%$ com indicação do ajuste linear para determinação das constantes elásticas de cada condição são ilustradas na Figura 3. Aumentando os valores de tensão e de deformação máxima, as membranas tornam-se mais flexíveis e deformáveis, deslocando o ponto de ruptura para deformações maiores do que aquelas das amostras não expostas à glicerina.

Para facilitar a compreensão dos resultados outro parâmetro relevante a ser considerado é a energia gasta com o trabalho de deformação por tração a partir da tensão inicial até a tensão máxima (Wu et al. 2004). Os valores da densidade de energia estão relacionados no Quadro 2 e foram obtidos pela determinação da área sob as curvas Tensão (MPa) X deformação ( $\mathrm{mm} / \mathrm{mm}$ ), que correspondem a energia requerida em cada ensaio. Valores de constante de elasticidade também estão expressos no Quadro 2.

Analisando-se o gráfico referente à força "versus" alongamento, obtidos por meio do software TescR, foi possível determinar algumas propriedades mecânicas dos corpos de prova estudados. Estas propriedades incluem força de tração, tensão e alongamento, do material a fresco e conservados em glicerina a 98\%, nos períodos de 30, 60 e 90 dias (Quadro 3).

Todas as variáveis apresentaram diferenças significativas $(\mathrm{p}<0,01)$, entre os tratamentos (dias), exceto a variável tensão máxima (T máxima), que não foi significativa $(p>0,05)$. A regressão polinomial que melhor se ajustou as variáveis significativas foi a regressão linear as quais estão expressas no Quadro 4.

Considerando-se a força máxima aplicada ao peritônio, evidenciou-se aumento nos valores para o material a fresco $(9,86 \mathrm{~N})$ conservado em glicerina a $98 \%$, por 30 dias $(7,97$ $\mathrm{N}), 60$ dias $(16,10 \mathrm{~N})$ e 90 dias $(18,83 \mathrm{~N})$, sendo estes significativos $(\mathrm{p}<0,01)$. Com relação a variável alongamento,

Quadro 2. Constante elástica, densidade de energia e energia total gasta nos diferentes períodos de armazenamento da membrana

\begin{tabular}{lcccc}
\hline Parâmetros & \multicolumn{4}{c}{ Períodos analisados (dias) } \\
& 0 & 30 & 60 & 90 \\
Constante elástica & 7,12 & 3,36 & 2,58 & 3,97 \\
Densidade de energia (MJ/m3) & 0,153 & 0,128 & 0,329 & 0,861 \\
Energia total gasta (mJ) & 9,0 & 8,0 & 10,4 & 17,4
\end{tabular}

Quadro 3. Valores referentes a avaliação do peritônio de paca submetidos ao ensaio mecânico de tração, a fresco (dia 0) e conservado em glicerina $98 \%$, nos períodos de 30, 60 e 90 dias, expressos pela media \pm desvio padrão. Jaboticabal, 2009

\begin{tabular}{lccccc}
\hline Dias & $\begin{array}{c}\text { Espessura } \\
(\mathrm{mm})\end{array}$ & $\begin{array}{c}\text { Área } \\
\left(\mathrm{mm}^{2}\right)\end{array}$ & $\begin{array}{c}\text { Força Máxima } \\
(\mathrm{N})\end{array}$ & $\begin{array}{c}\text { Tensão } \\
(\mathrm{MPa})\end{array}$ & $\begin{array}{c}\text { Alongamento } \\
(\mathrm{mm})\end{array}$ \\
\hline 0 & $0,5 \pm 0,07$ & $5,40 \pm 0,70$ & $9,86 \pm 3,59$ & $1,84 \pm 6,96$ & $9,00 \pm 3,48$ \\
30 & $0,45 \pm 0,15$ & $4,50 \pm 1,51$ & $7,97 \pm 4,16$ & $1,75 \pm 6,79$ & $14,94 \pm 5,97$ \\
60 & $0,90 \pm 0,45$ & $9,00 \pm 4,55$ & $16,10 \pm 4,69$ & $2,18 \pm 1,12$ & $19,86 \pm 7,84$ \\
90 & $0,72 \pm 0,30$ & $7,20 \pm 3,05$ & $18,83 \pm 7,33$ & $2,79 \pm 2,79$ & $22,18 \pm 10,70$
\end{tabular}

Quadro 4. Equações das regressões lineares para as variáveis (espessura, forca, alongamento, área) representados pela letra $y$, em função de $x$ (dias)

\begin{tabular}{lcc}
\hline Variável $(\mathrm{y})$ & Regressão $(\mathrm{y}=\mathrm{a}+\mathrm{b} . \mathrm{x})$ & Valor de $\mathrm{p}^{*}$ \\
\hline Espessura $(\mathrm{mm})$ & $0.500+0.0033 . \mathrm{x}$ & $0.030^{*}$ \\
Força $(\mathrm{N})$ & $7.931+0.1168 . \mathrm{x}$ & $0.000^{* *}$ \\
Alongamento $(\mathrm{mm})$ & $9.826+0.1482 . \mathrm{x}$ & $0.000^{* *}$ \\
Área $\left(\mathrm{mm}^{2}\right)$ & $5.040+0.033 . \mathrm{x}$ & $0.030^{*}$
\end{tabular}

${ }^{* \mathrm{p} \leq 0,05 \text { significativo a } 5 \% .{ }^{* *} \mathrm{p} \leq 0,01}$ significativo a $1 \%$ de probabilidade. 
notou-se aumento nos valores relativos aos materiais conservados em glicerina, verificando-se diferença significativa $(p<0,01)$ entre os valores das amostras a fresco $(9,00$ $\mathrm{mm}$ ) e os preservados por períodos de 30 dias $(14,94 \mathrm{~mm})$ ,60 dias $(19,86 \mathrm{~mm})$ e 90 dias $(22,18 \mathrm{~mm})$, indicando que os valores da amostras aumentaram em relação ao alongamento em 0,1482mm por dia.

A variável área também se apresentou significativa $(p<0,01)$ entre os valores das amostras a fresco $\left(5,40 \mathrm{~mm}^{2}\right)$ e os preservados em glicerina pelos períodos de 30 dias $\left(4,50 \mathrm{~mm}^{2}\right), 60$ dias $\left(9,00 \mathrm{~mm}^{2}\right)$ e 90 dias $\left(7,20 \mathrm{~mm}^{2}\right)$, indicando assim, que a área desta membrana aumentou em $0,033 \mathrm{~mm}^{2}$ por dia.

\section{DISCUSSÃO}

As curvas de força $\mathrm{F}(\mathrm{N})$ contra deformação $\Delta \mathrm{x}(\mathrm{mm})$, normalmente obtidas em ensaios mecânicos, neste estudo com o peritônio da paca, podem ser apresentadas na forma de tensão $\mathrm{T}(\mathrm{Pa})$ contra a deformação relativa $\Delta \mathrm{x} / \mathrm{x}$. A taxa de variação da tensão dividida pela taxa de variação da deformação é, a princípio, independente das dimensões iniciais do material. Assim o parâmetro $\Delta \mathrm{T} /(\Delta \mathrm{x} / \mathrm{x})$, ou seja, a inclinação dos trechos lineares é um parâmetro que mede a constante elástica do trecho considerado (Asby \& Jones 1996). No caso de materiais complexos como polímeros, borrachas e membranas biológicas, mesmo para pequenas deformações, o comportamento mecânico pode não seguir um regime linear com relações entre força e deformação, que dependem da própria deformação, e este é o caso das amostras investigadas neste trabalho conforme ilustrado na Figura 2.

As constantes elásticas determinadas em cada trecho e consideradas "linear" na Figura 2, podem ser comparadas ao modulo de Young dos materiais elásticos. Considerando a semelhança do comportamento entre o peritônio de paca e o peritônio bovino analisado por Guimaraes et al. (2008), nota-se que a glicerina diminui a rigidez dos tecidos evidenciando um aumento da elasticidade.

Observando os valores de força máxima, tensão máxima, tensão média dos valores máximo e deformação máxima para os ensaios realizados, verificou-se que o efeito da glicerina é de aumentar tanto a tensão máxima quanto a deformação máxima.

Constatou-se ainda, que o aumento no tempo de conservação em glicerina, promovia diminuição da rigidez da membrana. Tal situação foi evidenciada pela diferença nos valores de alongamento observados tanto nas amostras analisadas a fresco, quanto naquelas conservadas em glicerina pelos períodos de 30 dias, 60 dias e 90 dias. Estas informações se assemelham às observações de Abrahao et al. (1992), ao relatarem diferenças significativas para o alongamento do peritônio bovino a fresco e conservado em glicerina por 60 dias.

Outro aspecto a ser considerado na análise das curvas (Tensão "versus" Taxa de deformação) é que o aumento do comprimento devido à tração mecânica implica em uma redução da área da secção transversal. Assim, nas deformações plásticas o material escoa, levando a diminuição da secção transversal associada ao aumento do comprimento. Este fenômeno é evidenciado na queda da tensão nominal (que considera a área da secção transversal constante) antes do rompimento do material (Asby \& Jones 1996).

Ao se analisar atentamente a Figura 2, verifica-se uma brusca variação na tensão, situação que se apresenta de forma semelhante na ilustração da Figura 3 (deslizamento de discordâncias) e corresponde possivelmente às alterações ou rompimento das fibras colágenas do peritônio, ocorrência esta, predominante nas amostras a fresco. Analisando-se o Quadro 2 nota-se um substancial aumento da densidade de energia das amostras de peritônio de paca conservadas em glicerina, consistindo-se assim em um parâmetro indicador da melhoria das propriedades mecânicas das membranas armazenadas em glicerina, observações também exaradas por Guimaraes et al. (2008).

Ao testarem e compararem a resistência à tração e ao alongamento, até a ruptura do centro tendíneo bovino a fresco, conservado em glicerina a $98 \%$ e conservado em glutaraldeido a 4\%, por 30 dias, Rabelo et al. (2004) concluíram, mediante análise dos valores médios obtidos para a força máxima de tração, que o material conservado em glutaraldeido a 4\% apresentava incremento significativo em sua resistência, quando comparado ao material preservado em glicerina a 98\%. 0 entendimento do real significado destes resultados fica comprometido, pois a força máxima depende também da espessura do material, medida cuja acurácia pode ser comprometida, por erros sistemáticos e também pelas próprias características do material; assim, no presente trabalho preferiu-se determinar e analisar as curvas de tensão $\mathrm{x}$ deformação relativa.

Neste trabalho buscou-se estabelecer parâmetros de referência com base na estimativa dos erros envolvidos, procurando representar somente os algarismos que podem ser significativos e voltando a atenção para dois parâmetros principais: uma constante elástica definida na região inicial do alongamento, ou seja, com deformação relativa, variando em torno de 0,05 (5\%) e na integração das curvas tensão contra deformação relativa, que fornece a densidade de energia envolvida na deformação do material. Assim, verificou-se que as constantes elásticas típicas estão entre alguns $\mathrm{MPa}$, podendo chegar próximo de $20 \mathrm{MPa}$. As tensões e deformações relativas máximas para as membranas de peritônio de paca, embora, menores que a dos bovinos (Rabelo et al. 2004) apresentam características muito semelhantes com relação à armazenagem em glicerina, ou seja, a glicerina torna as forças de ruptura e as deformações relativas maiores do que aquelas amostras que não foram armazenadas nesta substância.

A densidade de energia mecânica de cada material é um parâmetro bastante característico e que representa bem o fato da glicerina contribuir para a chamada melhoria das propriedades elásticas das membranas. Este parâmetro mostra valores que crescem de $0,2 \mathrm{MJ} / \mathrm{m} 3$ para o peritônio de paca a fresco ate $0,9 \mathrm{MJ} / \mathrm{m} 3$, no caso do peritônio conservado em glicerina $98 \%$ por 90 dias. A energia requerida para deformações definidas pode ser calculada a partir da densidade de energia determinada em experimentos de tração, consistindo em parâmetro útil na avaliação de desempenho da membrana.

Constatou-se que ambas, análises dos parâmetros elás- 
ticos característicos com os respectivos algarismos significativos, determinados com base no erro provável e na análise estatística dos dados, culminaram em resultados semelhantes, embora os valores de tensão, na análise estatística, apresentaram desvios padrões maiores que a própria média (Tabela 4), perdendo-se assim o significado destes erros, que indicariam a possibilidade de constantes elásticas negativas.

\section{CONCLUSÕES}

Concluiu-se que a glicerina $98 \%$ é uma substancia eficiente para a conservação de membranas biológicas, melhorando as propriedades mecânicas e permitindo que as membranas suportem maiores forças de deformação.

Os resultados obtidos nos ensaios mecânicos do peritônio da paca conservado em 30, 60 e 90 dias sugerem sua utilização como mais uma opção de material biológico para o uso em cirurgias reconstrutivas.

Para se avaliar o real papel funcional dessa estrutura, quando utilizado como implante, é fundamental a realização de estudos detalhados e aplicados, relacionados as experimentações "in vivo", respeitando a ética e o bem estar animal.

\section{REFERÊNCIAS}

Abrahao M.S., Shimano A.C., Paulin J.B.P. \& Daleck C.R. 1992. Estudo comparativo da resistência à tração do peritônio de bovino a fresco e conservado em glicerina. In: 1o Fórum Nacional de Ciência e Tecnologia em Saúde, Caxambu, MG. SBEB, Caxambu, p.22-25. (Resumo expandido)

Alvarenga J. 1992. Possibilidades e limitações da utilização de membranas biológicas preservadas em cirurgia, p.33-42. In: Daleck C.R., Baptista L.C. \& Mukai L.S. (Eds), Tópicos em Cirurgia de Cães e Gatos. FunepUnesp, Jaboticabal.

Asby M.F. \& Jones D.R.H. 1996. Engineering Materials 1: an introduction to their properties and applications. $2^{\text {nd }}$ ed. Butterworth Heinemann, Oxford, p.88, 94, 96.

Batista L.C., Daleck C.R., Shimano A.C., Alessi A.C. \& Abrahao M.S. 1996. Estudo comparativo da resistência a tração do peritônio (bovino, equino, suíno e canino) a fresco e conservado em glicerina. Braz. J. Vet. Res. Anim. Sci. 33:305-312.

Baungarten L.B., Freitas P.M.C., Salgado A.E.P., Eurides D., Camilli R.A., Silva G.M., Daleck C.R. \& Silva L.A.F. 2006. Avaliação clinica da blefaroplastia em coelhos com cartilagem auricular alógena conservada em solução saturada de sal ( $\mathrm{NaCl})$. Vet. Notícias 12(2):32.

Camargo A.D., Leal L.M., Garcia Filho S.P., Martins L.L., Dos Reis A.C.G. \& Machado M.R.F. 2012. Propriedades morfológicas do peritônio da paca (Cuniculus paca, L. 1766) a fresco e conservados em glicerina 98\%. Biotemas 25(4):185-192.

Chehuen Neto J.A., Nigro A.J.T., Belmonte Netto L. \& Goldenberg S. 1991. Restauração traqueal com enxerto cartilaginoso autólogo de pavilhão auricular: estudo experimental em coelhos. Acta Cir. Bras. 6(4):169-176.

Contesini E.A., Salles M.S., Pigatto J.A.T. \& Santos S.C. 2001a. Reparação traqueal em cães: transplante autógeno vs implante homogêneo conservado em glicerina a 98\% de cartilagem da pina. Ciência Rural 31(4):633637.

Contesini E.A., Krauspenhar L.C., Pippi N.L., Brun M.V., Beck C.A.C., Bonfada A.T., Silva T.F., Trindade A.B., Costa J.S.C., França E.P. \& Lima L.T. 2001b. Influencia antibiótica no reparo tardio com uso da pina auricular conservada em glicerina a $98 \%$ em cães. Anais 22 ㅇ Congresso Brasileiro de Clínicos Veterinários de Pequenos Ànimais, Fortaleza, p.166. (Resumo)

Costa J.L.O., Padilha Filho J.G., Costa C.M.B. \& Santos P.C. 2004. Acetabuloplastia extracapsular em caes com cartilagem auricular de bovino conservada em glicerina. Revta Cient. Eletron. Med. Vet. 2:1-2 <http:// www.revista.inf.br/veterinaria02/>
Costa Neto J.M., Daleck C.R., Alessi A.C. \& Braccialli C.S. 1999. Tenoplastia experimental do calcâneo em cães com peritônio bovino conservado em glicerina. Ciência Rural 29(4):697-703.

Daleck C.R., Daleck C.L.M., Alessi A.C., Padilha Filho J.G. \& Costa Neto J.M. 1988. Substituição de um retalho diafragmático de cão por peritônio de bovino conservado em glicerina: estudo experimental. Ars Vet. 4(1):53-61.

Daleck C.R., Daleck C.L.M., Padilha Filho J.G. \& Costa Neto J.M. 1992. Reparação de hérnia perineal em cães com peritônio de bovino conservado em glicerina. Ciência Rural 22(2):179-183.

Eisenberg J.F. \& Redford K.H. 1999. Mammals of the Neotropics. 2. The southern cone. University of Chicago Press, Chicago. 430p.

Guimarães G.C., Machado M.R.F., Shimano A C., Tercariol C.A.S., Volpon J.B. \& Daleck C.R. 2008. Propriedades tensiometricas comparadas do centro tendíneo, pericárdio e peritônio de bovinos a fresco e conservados em glicerina. Braz. J. Vet. Res. Anim. Sci. 45:127-135.

Hamlet W.C. \& Rasweiler IV J.J. 1993. Comparative gestation and placentation in vertebrates. J. Exp. Zoology 266:343-346.

Lange R.R. \& Schmidt E.M.S. 2007. Rodentia: roedores silvestres (capivara, cutia, paca, ouriço), p.475-491. In: Cubas Z.S., Silva J.C.R. \& Catão Dias J.A. (Eds), Tratado de Animais Selvagens: medicina veterinária. Roca, São Paulo.

Leite J.B.F., Marques A.F., Gomes O.M. \& Pigossi N. 1979. A glicerina e a preservação dos tecidos. Revta Paulista Med. 93(3/4):81-84.

Pachaly J.R., Acco A., Lange R.R., Nogueira T.M.R., Nogueira M.F. \& Ciffoni E.M.G. 2001. Order Rodentia (rodents), p.225-237, In: Fowler M.E \& Cubas Z.S. (Eds), Biology, Medicine, and Surgery of South American Wild Animals. Iowa State University Press, Ames.

Pigatto J.A.T., Pippi N.L., Marchionatti A., Contesini E.A., Graça D.L., Godoy C.L.B. \& Souza R.L. 1998. Esofagoplastia cervical em caninos com enxerto homólogo de cartilagem conchal preservada em glicerina. Ciência Rural 28(4):617-621.

Pigossi N. 1964. Implantação de dura-máter homógena conservada em glicerina: estudo experimental em cães. Tese de Doutorado, Faculdade de Medicina, Universidade de São Paulo, São Paulo. 41p.

Pigossi N. 1967. A glicerina na conservação de dura-máter: estudo experimental.. Tese de Livre Docência, Faculdade de Medicina, Universidade de São Paulo, São Paulo. 83p.

Pigossi N., Raia A., Lex A., Gama A.H., Simonsen O., Haddad J., Stolf N., Zerbini E.J., Miniti A. \& Tenuto R. 1971. Estudo experimental e clinico sobre o emprego como implante da dura-máter homógena conservada em glicerina a temperatura ambiente. Revta Assoc. Med. Bras. 17(8):263-278.

Queirolo D., Vieira E., Emmons L. \& Samudio R. 2008. Cuniculus pacq. In: IUCN (Ed.), Red List of Threatened Species. Disponível em <www.iucnredlist.org> Acessado em 1 mai. 2009.

Rabelo R.E., Tavares G.A., Paulo N.M., Silva L.A.F., Damasceno A.D., Andrade M.A., Martins F.G., Romani A.F., Silva O.C. \& Trindade B.R. 2004. Características físicas e microbiológicas do centro tendíneo diafragmático bovino conservado em glicerina a $98 \%$ e no glutaraldeído a 4\%. Ciênc. Anim. Bras. 5(4):229-238.

Rodaski S., Cunha O., De Nardi A.B., Rios A., Comar F.A. \& Castro J.H.T. 2002. Artroplastia acetábulo-femoral em cães com pericárdio bovino conservado. Archs Vet. Sci. 7(2):179-187.

Saporito W.F., Pires A.C., Cardoso S.H., Correa J. A., De Abreu L.C., Valenti V.E., Miller L.M. \& Colombari E. 2011. Bovine pericardium retail preserved in glutaraldehyde and used as a vascular patch. BMC Surg.11(37):1-8.

Sartori Filho F., Gandolfi W. \& Bandarra E.P. 1997. Emprego da membrana biológica (centro frênico) na reparação das lesões tendíneas em coelhos. Vet. Zootec. 9:69-77.

Schaum D. \& Van Der Merwe C.W., 1973. Física geral. McGraw-Hill, São Paulo. 430p.

Wells P.B., Yeh A.T. \& Humphrey J.D. 2006. Influence of glycerol on the mechanical reversibility and thermal damage susceptibility of collagenous tissues. IEEE Trans. on Bio. Engin.53(4):747-753.

Wu C., Lee H.D., Machado R.B., Dalmas S., Coy C.S.R., Goes J.R.N. \& Fagundes J.J. 2004. Apresentação do teste energia total de ruptura para avaliação de material biológico com propriedade viscoelástico não-linear. Acta Cir. Bras. 19(6):609-619. 